\title{
A Narrative Account of Nottingham University Hospitals NHS Trust Critical Care Response to the COVID-19 Pandemic, and Analysis of Outcomes
}

\author{
Amar Javaid \\ Nottingham University Hospitals NHS Trust \\ Joel Swindin \\ Nottingham University Hospitals NHS Trust \\ Richard Greenhow \\ Nottingham University Hospitals NHS Trustunitedkin \\ Marc Chikhani ( $\square$ marc.chikhani@nottingham.ac.uk) \\ Nottingham University Hospitals NHS Trust https://orcid.org/0000-0002-6449-8317
}

\section{Research}

Keywords: COVID-19, SARS-CoV-2, ventilation, renal replacement therapy, thrombosis, mortality

Posted Date: October 26th, 2020

DOI: https://doi.org/10.21203/rs.3.rs-95525/v1

License: (a) (i) This work is licensed under a Creative Commons Attribution 4.0 International License.

Read Full License 


\title{
A narrative account of Nottingham University Hospitals NHS Trust critical care response to the COVID-19 pandemic, and analysis of outcomes
}

\author{
Authors \\ Amar Javaid, Joel Swindin, Richard Greenhow, Marc Chikhani * \\ On behalf of the Nottingham University Hospitals NHS Trust Critical Care Research Group
}

\begin{abstract}
Affiliation
Critical Care Department, Nottingham University Hospitals NHS Trust, England, UK.

* corresponding author marc.chikhani@nottingham.ac.uk
\end{abstract}

\section{Abstract \\ Background}

The novel coronavirus SARS-CoV-2 and associated multisystem disease COVID-19 originated in Wuhan, China in December 2019. The resultant pandemic has resulted in an unprecedented strain on healthcare services around the world, including the greatest challenge seen by critical care medicine in modern times. This narrative illustrates the response of Nottingham University Hospitals NHS Trust critical care department to the crisis, including resource allocation and clinical management strategies and illustrates patient outcome for those admitted to critical care during the first pandemic wave.

\section{Methods}

Patients admitted to critical care whom tested positive for SARS-CoV-2 between March-May 2020 were identified for retrospective case review as part of service evaluation. Clinical, laboratory and radiological data was collected. This included patient level data on ventilation and fluid balance.

Results

During the three period March-May 2020, retrospective case review showed 109 patients admitted to critical care with COVID-19. 88 (80.7\%) of the 109 patients received mechanical ventilation, 21 (19.3\%) patients received renal replacement therapy. Critical care mortality was 26 (23.9\%) patients and hospital mortality was $27(24.8 \%)$ of the 109 patients.

\section{Conclusion}

This mortality rate was an unexpected finding based on early literature and help to provide a baseline for comparison hereafter. Commentary is provided for several aspects of care that may account for the low mortality rate and warrant further investigation in the future.

\section{Keywords}

COVID-19, SARS-CoV-2, ventilation, renal replacement therapy, thrombosis, mortality

\section{Introduction}

The emergence of severe acute respiratory syndrome coronavirus 2 (SARS-CoV-2) from Wuhan, China in December 2019,(1) with its progression to the coronavirus disease 2019 (COVID-19)(2) global pandemic has presented the greatest worldwide challenge to critical care medicine since the origin of the speciality during the $20^{\text {th }}$ century polio epidemic.

With over 36 million cases and 1 million deaths globally,(3) the logistical obstacles and influx of patients, alongside a rapidly evolving understanding of a novel disease, have triggered the largest 
concerted effort by healthcare systems across the globe on a scale unwitnessed by most practising clinicians. Given the paucity of published research to inform clinical decision making early on in the pandemic, it is unsurprising to see mortality rates, for those ventilated in critical care, over $50 \%,(4-7)$ and in some instances approaching $90 \% .(8,9)$

To date, minimal outcome data from individual UK intensive care units is available. More recent data suggest mortality rates are improving,(10-12) as patient numbers decline coupled with better understanding how to treat those critically ill with COVID-19.

Given the wide variation in COVID-19 ICU mortality,(13) the authors describe the approach of their critical care department to this crisis; including logistics, resource allocation, and clinical management strategies; and finish with an analysis of our outcomes, with the aim to disseminate our findings and add to the stock knowledge of the subject in anticipation of further surge in COVID19 incidence.

\section{Methods}

The proposed method of retrospective observational analysis of routinely collected anonymous data was registered as a service evaluation with the NUH clinical effectiveness department (reference 20314C).

All patients admitted to Nottingham University Hospitals critical care (NUHCC) department between $10^{\text {th }}$ March 2020 and $31^{\text {st }}$ May 2020 who tested positive for SARS-CoV-2 were identified. Medical records of these patients were retrospectively reviewed. The demographic and clinical data required for submission to the Intensive Care National Audit and Research Centre (ICNARC) was combined with observation recordings, laboratory results and radiology reports.

Ventilation data was obtained from manual search of the 0800 and 2000 time points for the first 7 days of mechanical ventilation, and fluid balance reviewed from admission to the earliest occurrence of renal replacement therapy, discharge (including death) from critical care, or day 10 of critical care treatment. Data collection was carried out by the authors working on critical care during the COVID19 pandemic.

\section{Critical Care at Nottingham University Hospitals NHS Trust}

Nottingham University Hospitals (NUH) NHS Trust is a large tertiary hospital in the United Kingdom, with around 1700 acute care beds across two sites - The Queen's Medical Centre (QMC) and The Nottingham City Hospital (NCH). The emergency department receives over 180000 attendances per year. NUH serves as the regional major trauma and neurosciences centre, providing acute and elective services to the 2.5 million residents of Nottinghamshire, and tertiary services to 3-4 million residents within the East Midlands.

Prior to the emergence of COVID-19, critical care at NUH was commissioned for 21 level 3 and 20 level 2 beds at QMC, and 17 level $2 / 3$ beds at $\mathrm{NCH}$ and an additional cardiac critical care unit with capacity for 16 level $2 / 3$ beds with around 4500 total admissions to critical care per annum.

\section{Planning}

Contingency planning, including segregation of current facilities into COVID-19 and non-COVID-19 areas with identification of potential locations for continued surge conditions, was underway in late February. The release of an email communication via the European Society of Intensive Care Medicine (ESICM) from Northern Italy,(14) served as a catalyst to accelerate preparations. 
Reaching near capacity in an existing critical care area would trigger admission to sequential preidentified isolated areas including operating theatre pod complexes. Surge plans were constantly reviewed and amended to adapt to the evolving situation. To minimise the number of geographically discrete critical care areas within the hospital, additional physical partitioning walls and gowning lobbies were rapidly constructed to provide cohort areas within existing open floorplan areas. This was in part made possible given the marked early reduction and subsequent cessation of elective surgical work, and transient fall in non-COVID-19 critical care admissions.

Reduction in elective work followed by its cessation on $12^{\text {th }}$ March, as the first isolated COVID-19 cohort area was utilised, provided an opportunity of around two weeks prior to high frequency surge of COVID-19 admissions. This allowed for iterative development of local protocols, practical guides and checklists for donning and doffing personal protective equipment (PPE), conduct of rapid sequence induction (RSI) and intubation for respiratory failure, emergency assessment, retrieval and transfer of patients to critical care, and prone positioning. Critical care staff were targeted for FFP3 mask fit testing with drop in 'PPE clinics' for staff to familiarise themselves with donning and doffing procedures. Simulation training took place for all those involved in intubation, transfer and prone positioning of patients with suspected COVID-19 whilst wearing PPE appropriate for aerosol generating procedures (AGP).

\section{Staffing}

\section{Critical care consultants}

By mid-March a shadow rota for non-resident on-call consultants to be available day and night to provide additional cover as required was in place. On $30^{\text {th }}$ March the shadow rota was combined with the general critical care rota to provide round the clock consultant cover. With 33 critical care consultants, there was the ability to allocate at least one to each of the critical care areas until 8pm, even at maximum surge capacity. In addition, there was an allocated lead consultant to co-ordinate referrals, transfers and beds. At each hospital site, overnight cover consisted of two consultants, one resident and one non-resident after 0200 . The expanded rota allowed maintenance of our usual level of consultant involvement in daily clinical decision making and bed management on a day-today basis. All programmed activities (PAs) in alternate specialties for dual trained intensivists were utilised for direct clinical care (DCC) in critical care.

\section{Anaesthetic department support}

A full complement of emergency care, including adult and paediatric emergencies, trauma and obstetric lists was preserved throughout. All emergency and on-call tiers were covered with normal levels of staffing.

Early reduction in elective surgical workload meant there was sufficient liberation of anaesthetic trainees to support rotas in critical care. Consultant anaesthetists backfilled anaesthetic trainee oncall commitments 24-hours a day, with enhanced levels of on-call out of hours, both resident and non-resident. Anaesthetic teams were responsible for the rescue and transfer of emergency admissions from the emergency department to critical care, including inter-hospital transfer between the two hospitals within the trust.

\section{Junior medical staff}

Pooling of trainees from anaesthetics, medicine and academic training programmes allowed the number of whole time equivalent (WTE) trainees and fellows to be increased from 40 to 98 at peak capacity. Out of hours cover for each critical care area, including surge areas, comprised a minimum of two trainees at all times, at least one of whom with competence in advanced airway management and procedural skills appropriate to critical care. 
Nursing staff

Around 350 registered critical care nurses work at NUH. They worked flexibly between sites and areas with increased oversight from the senior nursing team. With the support of theatre nurses and operating department practitioners (ODPs) they were able to provide one to one, nurse to patient, ratios. At maximum surge there was a minimum of one registered critical care nurse to two patients (supported by non-ICU nurses and ODPs).

\section{Clinical}

Guidance

Groups of senior nurses and consultants were established to agree and write clinical guidelines to allow critical care to be delivered by non-critical care staff in the event of a sustained surge. Version control was important given the rapid evolution of clinical knowledge, evidence base and subsequent changes in guidance. As a consultant body it was accepted that recommendations put forward by each group were reviewed for omissions and errors rather than a wholesale change in content, this was vital to ensure rapidity of dissemination and implementation. All guidance was reviewed by the critical care governance lead.

\section{Ventilation}

Initial ventilation guidance was formulated without any first-hand experience of managing COVID19. It was focussed around the principles of managing acute respiratory distress syndrome (ARDS) and viral pneumonitis; with lung protective ventilation comprising a low tidal volume and high positive end expiratory pressure (PEEP),(15) paralysis,(16) and prone positioning for refractory hypoxia,(17) this was disseminated by $31^{\text {st }}$ March.

Local experience of COVID-19 was not typical of the disease described in early literature, $(4,8,18,19)$ prompting the need for rapid evolution of the guidance with a significantly different approach by $9^{\text {th }}$ April. This had features in common with recommendations from Guy's and St Thomas'.(20) The updated guidance suggested a starting PEEP of $0.1 \mathrm{~cm} \mathrm{H}_{2} 0 . \mathrm{kg}^{-1}$, used a low PEEP-FiO 2 ladder, lung protective tidal volume and permissive hypercapnia to a $\mathrm{pH}$ of $7.15 . \mathrm{SpO}_{2}$ target was $88-92 \%$, and we strictly adhered to targeting $\mathrm{SpO}_{2}$ rather than $\mathrm{PaO}_{2}$. A summary of the ventilation strategy can be found in Appendix I.

Prone position ventilation was observed to markedly improve oxygenation and this was subsequently encouraged as an early intervention rather than rescue intervention for hypoxaemia. Dedicated prone positioning teams were used to facilitate this.

Initial national guidance advised the use of dry ventilation circuits with a heat and moister exchange filter (HME) at the patient end.(21) Difficulties were encountered with saturation of the HME filter and with mucous plugging. By $11^{\text {th }}$ April, practice was changed to allow consultant consideration of the use of warmed and humidified (water bath) breathing circuits after an initial time period with HME where risks of COVID-19 transmission was thought to be outweighed by the risk of adverse events from impaired HME filter performance.

NUH was asked to expand ventilator bed capacity to 186 , the latest surge plan had accounted for 167 ventilated beds. At peak surge we had 57 simultaneous confirmed COVID-19 patients within critical care.

In addition to around 60 existing critical care ventilators, coincidental prior acquisition of replacement ventilators meant there were a further 50 available critical care ventilators to supply surge locations. The challenge of training staff on new ventilators and anaesthetic machines was undertaken on an accelerated timetable with the use of bespoke quick reference guides and face-to- 
face sessions. The existing and new ventilators were cohorted at $\mathrm{QMC}$ and $\mathrm{NCH}$ respectively and this helped to minimise the population of staff requiring training on both machines. Expanded ventilator capacity meant that almost all patients with COVID-19 were ventilated with dedicated critical care ventilators.

Oxygen supplies were physically checked for each critical care area including surge area, and usage was monitored daily.

\section{Tracheostomy}

In anticipation of a large cohort of ventilator dependent patients with COVID-19, plans were drawn up to increase capacity for tracheostomy insertion. UK and international guidance,(22) suggested that delegation of tracheostomy insertion to the surgical teams seemed a prudent use of resources and may be preferable given concerns regarding infection control and aerosol generation during percutaneous tracheostomy.(23)

Given the local experience of over 200 percutaneous tracheostomy insertions per year within NUH critical care, decision for mode of tracheostomy insertion remained at the discretion of the critical care consultant. Updated procedural guidance was circulated suggesting that the routine modified percutaneous Ciaglia technique(24) was continued but altered to minimise aerosol generation by pausing ventilation during bronchoscopy and tracheal dilation and clamping of the breathing circuit prior to disconnection.

\section{Fluid management and renal replacement therapy}

Initially, a restrictive fluid approach was recommended, aiming for even to slightly negative daily fluid balance based on current practice. $(15,25)$ This was to be achieved using diuretics and renal replacement therapy (RRT) if required. As the ventilation guideline was changed, so our approach to fluid management was liberalised, aiming for euvolaemia, avoiding the use of diuretics and preserving RRT for the usual indications of acute kidney injury.

RRT during the COVID-19 surge was in keeping with routine local practice - continuous veno-venous haemo(dia)filtration (CVVH(DF)). In anticipation of high demand and in order to preserve filter and circuit consumables several non-routine recommendations were made - routine left internal jugular central line insertion, preserving the right internal jugular for wide bore duel-lumen RRT cannulae. A higher proportion of pre-dilution (70\%) was preferred. The effluent rate prescribed was maintained at $35 \mathrm{ml} . \mathrm{kg}^{-1}$.hour, but as the consumables supply chain was stretched a dose of $25 \mathrm{ml} . \mathrm{kg}^{-1}$.hour was preferred. Low molecular weight heparin (LMWH) remained the first line anticoagulant of choice Appendix II). NCH has the water supply, staffing and equipment to deliver intermittent haemodialysis, this became a valuable resource as the pandemic stretched the supply chain of CVVH consumables.

\section{Pharmacological thromboprophylaxis}

Early observation showed COVID-19 patients with frequency of thrombotic complications exceeding those anticipated in normal practice. Fastidious weight-based augmentation of thromboprophylaxis preceded collaboration with haematology $\left(9^{\text {th }}\right.$ April) and subsequent Factor-Xa guided higher doses thromboprophylaxis for COVID-19 patients in critical care on $30^{\text {th }}$ April (Appendix III). Therapeutic anticoagulation was reserved for those with either demonstrated or high suspicion of thromboses where clinical instability precluded cross sectional contrast imaging.

\section{Rationalisation of medication}

Pharmacy support was increased to provide seven-day cover for the duration of the pandemic surge. Use of routine agents was dictated by national and local availability and procurement. Propofol was 
spared for critical care by encouraging the use of volatile anaesthesia intraoperatively. The local sterile production unit provided support by supplying batches of ready to use infusions such as noradrenaline and insulin. Where compatibility data existed, drugs were drawn into the same syringe to conserve consumables and infusion devices, such as combined morphine and midazolam. As soon as practicable, intravenous sedation was changed to enteral sedation to further liberate infusion devices.

\section{Rehabilitation}

Each surviving patient with COVID-19 was discharged to what became a bespoke dedicated rehabilitation unit. There was input from the respiratory and rehabilitation team, with specialist physiotherapy, speech therapy, occupational therapy, psychology and weekly input from critical care until ready for discharge home.

\section{Research}

NUH recruited patients to the REMAP-CAP,(26) RECOVERY,(27) ISARIC,(28) and GenOMICC(29) studies, three of which were already open. No patient received experimental treatment outside a clinical trial.

\section{Ethical principles}

Visiting was restricted in line with national guidance.(30) Daily routine structured telephone updates were provided to families. End of life discussions were led by consultants in person where possible. Small numbers of next of kin were allowed pre-arranged visits to patients under 18 years of age, and as part of end of life care, provided they themselves were not required to isolate.

A sub-group of consultants produced guidance considering the ethics of distributive justice,(31) faced with the real possibility of demand outstripping available resource. On the whole, normal criteria for critical care referral, assessment and admission were maintained, broadly consistent with NICE guidance.(32) There were no occurrences where critical care was denied on the basis of capacity. Local resource availability facilitated inter-hospital transfers within the critical care network to alleviate some pressure on local ICUs.

\section{Results}

During the time period between $10^{\text {th }}$ March and $31^{\text {st }}$ May 2020, there was in excess of 33000 attendances to acute admission wards and the emergency department, including over 4000 patients with suspected COVID-19. There were 1250 patients with confirmed COVID-19.

In total 109 patients were admitted to critical care with positive real-time reverse transcriptasepolymerase chain reaction ( $r R T-P C R$ ) SARS-CoV-2 infection from respiratory tract samples. This included 3 patients transferred in from network critical care units. Date of censoring for follow-up was $5^{\text {th }}$ June.

Baseline demographics and indicators of acute severity are shown in comparison with national data from ICNARC in Table 1.

A total of 84 (77.1\%) patients had at least one underlying medical comorbidity. The most common comorbidities were hypertension (50 patients, 45.9\%), obesity ([Body mass index (BMI) $>30] 47$ patients, 43.1\%), diabetes mellitus (32 patients, 29.4\%), hyperlipidaemia (21 patients, 19.3\%) and asthma (17 patients, 15.6\%). A median of 3 (IQR, 3-4) organ systems were supported. Median and mean APACHE II score was 15. 
Initial laboratory investigations are presented in Table 2. Leukocyte count at admission of greater than $11.0 \times 10^{9} . \mathrm{L}^{-1}$ was present in $31(28.4 \%)$ patients. Lymphocyte count of less than $1.0 \times 10^{9} . \mathrm{L}^{-1}$ was present in $68(62.4 \%)$ patients. Elevated CRP was present in all 109 (100\%) patients. Peak CRP during ICU stay was a median of $333 \mathrm{mg} / \mathrm{L}$ (IQR, 215-385). Peak ICU D-Dimer value was $2000 \mu \mathrm{g} . \mathrm{L}^{-1}$ (IQR, 1072-5327). A lactate greater than $1.6 \mathrm{mmol}^{-\mathrm{L}^{-1}}$ was present in $36(33.0 \%)$ patients on admission.

Thrombotic complications were diagnosed in 15 (13.8\%) patients. The majority of these were pulmonary emboli, in $9(60 \%)$ of the 15 patients. Large vessel venous thrombosis was seen in $3(20 \%)$ patients and evidence of thrombotic stroke in 5 (33.3\%) patients. Both pulmonary embolism and thrombotic stroke was demonstrated in 2 of 15 patients (Figure 1).

\section{Ventilation}

88 of the 109 critical care COVID-19 admissions received invasive mechanical ventilation. Outcome data was present for 79 patients, the paper based 24-hour charts were available for 55 patients. In total 2 (2.27\%) patients were transferred for extracorporeal membrane oxygenation (ECMO).

Median duration of ventilation for survivors was 19 days (IQR, 9-27), and 10 days (IQR, 5.8-12.8) for non-survivors (Table 3). Summary of the first seven days data for ventilation (Table 4) shows a reduction in PEEP, mean airway and peak pressure after the change in ventilation strategy. The median tidal volumes overall were $7.1 \mathrm{~mL} \mathrm{Kg}^{-1}(\mathrm{IQR}, 6.2-8.3)$, median driving pressure was $14 \mathrm{cmH}_{2} \mathrm{O}$ (IQR, 11-16). 22 (40\%) of 55 patients were ventilated in the prone position, and 36 (65\%) patients received an infusion of non-depolarising muscle relaxant during the first seven days of ventilation.

\section{Tracheostomy}

$41(47 \%)$ of the 88 invasively ventilated patients received a tracheostomy. $32(78 \%)$ were inserted percutaneously with the remainder surgical. Excluding the 2 patients who received ECMO, these were inserted between days 8 and 31 (median 14 days, mean 15 days). There were no tracheostomy associated deaths.

\section{Fluid balance and renal support}

The proportion of patients requiring RRT for acute kidney injury (AKI) varied throughout the pandemic surge. In the first three weeks of admissions, 11 (32\%) of 34 patients received RRT for AKI compared with 10 (15\%) of 68 patients admitted in subsequent weeks. The seven-day median daily fluid balance for patients admitted to ICU with COVID-19 in the first three weeks was $138 \mathrm{ml}$ positive (IQR, -310 to 802) compared to $620 \mathrm{ml}$ positive (IQR, -44 to 1235$)$ for patients admitted in subsequent weeks.

\section{Outcomes}

Critical care outcome data were available for 100 of 109 patients; cohort flow can be seen in Figure 2. Critical care mortality was 26 (23.9\%) patients, critical care discharge was 74 (67.9\%) patients, with $9(8.3 \%)$ patients remaining in critical care. Of those 74 patients discharged from critical care, 68 (91.9\%) patients have been discharged from hospital, 5 (6.8\%) patients remained in hospital and 1 (1.4\%) further patient died. Overall hospital mortality stood at 27 of the 109 patients (24.8\%).

The median critical care stay for survivors was 13 days (IQR, 7-27) and for those who died was 8 days (IQR, 4-11). For survivors, the median hospital length of stay was 24 days (IQR, 15-36) compared to 11 days (IQR, 7-18) for those who died. 
When considering those receiving invasive mechanical ventilation, outcome data was available for 79 of the 88 mechanically ventilated patients, 22 (27.8\%) patients died in critical care and $57(72.2 \%)$ patients were discharged from critical care. Hospital outcomes for 74 patients demonstrated no further deaths, 22 (29.7\%) patients; and 52 (70.3\%) patients had been discharged. The median duration of mechanical ventilation for survivors was 19 days (IQR, 9-27) compared to 10 days (IQR, 5.8-12.8) for those who died.

\section{Outcomes by admission variables}

Outcome by patient characteristics can be seen in Table 5 . Mortality was higher in those above 60 years of age, with the highest mortality (43.5\%) seen in the 60-69 year-old age group. The mortality rate in male and female patients with COVID-19 was $26.6 \%$ and $25 \%$ respectively. The difference observed was not as marked as in the national data (43.7\% vs $36.5 \%$ ).

The lowest mortality (20\%) was seen in those of Asian ethnicity, followed by Caucasian $(26.5 \%)$ and Black (30\%). The highest mortality was in those of mixed ethnicity $(50 \%)$ and those categorised as Other (50\%) although numbers in these groups were small ( 2 and 4 patients respectively).

Considering patient BMI demonstrated those with a BMI of less than $25 \mathrm{~kg} \cdot \mathrm{m}^{-2}$ had the highest mortality in our cohort at $37.9 \%$. Lowest mortality (18.2\%) was seen in those with a BMI between $30-40 \mathrm{~kg} \cdot \mathrm{m}^{-2}$.

Figure 3 shows the number of COVID-19 admissions, APACHE II score, cumulative number of patients in critical care and mortality by week of admission. Mortality was higher for those admitted in the first 5 weeks (30-50\%) compared to those admitted in the latter 7 weeks (0-9\%). An increase in mortality for the latter weeks is to be expected as 9 patients remain in critical care. The distribution of those developing thrombotic complications shows $13(86.7 \%)$ patients were admitted in the first 6 weeks of the period reviewed and $2(13.3 \%)$ patients in the latter 6 weeks (Figure 1).

\section{Discussion}

\section{Justification}

Observed critical care mortality rate of this cohort was $23.9 \%$, overall hospital survival was $75.2 \%$. The observed mortality within this cohort appears to be lower than that previously published,(4-9) and is more in keeping with recent data published from ICNARC. This pessimism was based on a flood of information from various news and social media sources outside the normal channels for clinical information. The intention of this evaluation of experience and knowledge gained during the pandemic surge was to identify plausible factors that may explain the variation in outcome data and facilitate discussion to improve overall care to COVID-19 patients.

Interpretation

Early reduction and then relocation of elective surgical workload to alternative providers allowed invaluable time to prepare COVID-19 surge areas and perhaps more importantly allow for development of systematic and comprehensive training in procedures in AGP PPE including intubation, transfer, and prone positioning. Bespoke guidance was developed in house preceding national publication by some weeks.(33)

The highest number of simultaneously ventilated patients with COVID-19 was 57, this was well below the maximum planned surge capacity of 167, thus NUH critical care was not overwhelmed with patients suffering from COVID-19. Staff ratios always ensured one to one care, at peak occupancy there was one registered critical care nurse for two patients supported by additional noncritical care staff. Consolidation of trainee rotas provided trainees with requisite skills to be deployed into every surge area. Critical care consultant presence was maintained at all times, including out of 
hours and every critical care patient was reviewed at least twice per calendar day by a critical care consultant.

Availability of critical care ventilators, surge capacity bed areas and staffing ratios mitigated the acuity of the resource strain and allowed for the delivery of critical care without the stress of nearing capacity and triaged admission policy.

An apparent reduction in critical care mortality, RRT and thromboses rate was observed following week six of the pandemic (Figure 1 and Figure 3). This was associated with changes in guidance for ventilation, RRT and thromboses, but may also reflect increased experience and familiarity with COVID-19.

Summary description of the ventilation parameters show similar median and mean averages for all parameters suggesting a paucity of outlier values. Tidal volume, driving pressure and peak pressure were always within ranges associated with survival benefit in ARDS.(34) Reduction of PEEP and subsequently mean airway, driving and peak pressure may have had a sparing effect on right ventricular function and global cardiac output.(35)

There was a marked reduction in the RRT rates as the pandemic progressed and coincided with an observed change in approach to fluid balance. Other plausible reasons may include preserved cardiac output with lower mean airway pressure, reduced use of RRT in pursuit of negative daily fluid balance and reduced intrarenal thrombus burden.

Decreased observed frequency of thromboses also occurred at around 6 weeks coinciding with an augmented thromboprophylaxis strategy, amended ventilation and RRT guidance.

\section{Limitations}

In-depth statistical analysis is not appropriate given the small cohort size and the heterogenous nature of the patients and there are potentially many confounding factors that could influence mortality. However, when compared to published datasets patient numbers are comparable if not favourable. $(4,5,7,11,12,36)$

Apparent improvement in mortality during the course of the pandemic surge may have occurred with increased exposure and familiarity in dealing with COVID-19 rather than as a result of evolution of clinical guidance.

Detailed ventilation data was missing in around one third of the patients due to delays in archiving paper-based notes or use of case notes by other teams.

Respiratory data collection was limited to seven days at two data points per day this was felt to be a good representation of the previous 12 hours of ventilation strategy and clinical condition.

\section{Extrapolation}

Submission of data to ICNARC has been essential for surveillance of critical care outcome data for the last 25 years, however collection of data on unit dependency, capacity, surge capacity and staffing levels could help to determine the interhospital variation in outcome and indeed seek to address inequalities between distribution of patients amongst hospitals in the same critical care network.

Collection and analysis of this patient cohort has provided the opportunity to establish baseline compliance with specifically produced guidance for the treatment of patients with COVID-19. 
Mortality appeared to improve during the latter half of the pandemic surge, this may reflect a number of rapid adaptations to clinical guidance alongside increased clinical experience, whilst maintaining the staffing capacity and resources to deliver high quality care.

\section{Conclusion}

As the first COVID-19 pandemic surge subsides in the UK the authors share experiences and learning points which were associated with a high survival rate. Focus on a whole system approach to management of patients with COVID-19 has established baseline data and identified several facets of care that warrant extended investigation in the future. 
Acknowledgments

Z Al-Rifai

I Antonopoulou

$\checkmark$ Banks

$M$ Beed

$T$ de Beer

J Bonnington

$P$ Candler

S Cantellow

M Ehlers

I Farquhar

F Fombon

K Fifield

D Gardiner

G Gibbon

$S$ Gill

D Harvey
A Howatson

$P$ James

I Johnson

$\mathrm{N}$ Lee

$M$ Levitt

$S$ Linford

A March

N Okonkwo

K Mohammed Rafi

G Sandhu

A Sharman

R Sherman

M Simmonds

D Sperry

C Watson 


\section{Declarations}

Ethics approval and consent to participate

The proposed method of retrospective observational analysis of routinely collected anonymous data was registered as a service evaluation with the NUH clinical effectiveness department (reference 20314C).

\section{Consent for publication}

Not applicable

Availability of data and materials

The datasets generated and analysed during the current study are not publicly available due to the information governance conditions of the institution further analysis is likely to be included in future research. Data are available from the corresponding author on reasonable request.

Competing interests

The authors declare that they have no competing interests.

Funding

No funding provided.

Author's contribution

All authors collected, collated, analysed and interpreted the data. All authors wrote, read and approved the final manuscript.

Acknowledgments

Acknowledgments are listed above.

Author's interests

All four authors are Consultants in Critical Care Medicine at Nottingham University Hospitals NHS Trust, Nottingham, United Kingdom and worked during the COVID-19 pandemic surge and were involved in the development of several of the guideline topics. 


\section{References}

1. World Health Organisation: Coronavirus Disease (COVID-19) - events as they happen.

https://www.who.int/emergencies/diseases/novel-coronavirus-2019/events-as-they-happen Edition.

2. European Centre for Disease Prevention and Control: Case definition for coronavirus disease 2019 (COVID-19), as of 29 May 2020. https://www.ecdc.europa.eu/en/covid-19/surveillance/casedefinition Edition.

3. Dong E, Du H, Gardner L: An interactive web-based dashboard to track COVID-19 in real time. Lancet Infect Dis 2020;20:533-534

4. Yang $X, Y u Y, X u$ J, et al: Clinical course and outcomes of critically ill patients with SARS-CoV-2 pneumonia in Wuhan, China: a single-centered, retrospective, observational study. Lancet Respir Med 2020;8:475-481

5. Bhatraju PK, Ghassemieh BJ, Nichols M, et al: Covid-19 in Critically III Patients in the Seattle Region - Case Series. N Engl J Med 2020;382:2012-2022

6. Liang WH, Guan WJ, Li CC, et al: Clinical characteristics and outcomes of hospitalised patients with COVID-19 treated in Hubei (epicentre) and outside Hubei (non-epicentre): a nationwide analysis of China. Eur Respir J 2020;55:10.1183/13993003.00562-2020. Print 2020 Jun

7. Nowak B, Szymanski P, Pankowski I, et al: Clinical characteristics and short-term outcomes of patients with coronavirus disease 2019: a retrospective single-center experience of a designated hospital in Poland. Pol Arch Intern Med 2020;130:407-411

8. Richardson S, Hirsch JS, Narasimhan M, et al: Presenting Characteristics, Comorbidities, and Outcomes Among 5700 Patients Hospitalized With COVID-19 in the New York City Area. JAMA 2020; 
9. Wang Y, Lu X, Li Y, et al: Clinical Course and Outcomes of 344 Intensive Care Patients with COVID19. Am J Respir Crit Care Med 2020;201:1430-1434

10. Zhang G, Hu C, Luo L, et al: Clinical features and short-term outcomes of 221 patients with COVID-19 in Wuhan, China. J Clin Virol 2020;127:104364

11. Mitra AR, Fergusson NA, Lloyd-Smith E, et al: Baseline characteristics and outcomes of patients with COVID-19 admitted to intensive care units in Vancouver, Canada: a case series. CMAJ 2020;

12. Zangrillo A, Beretta L, Scandroglio AM, et al: Characteristics, treatment, outcomes and cause of death of invasively ventilated patients with COVID-19 ARDS in Milan, Italy. Crit Care Resusc 2020;

13. Qian Z, Alaa AM, van der Schaar M, et al: Between-centre differences for COVID-19 ICU mortality from early data in England. Intensive Care Med 2020;

14. Cecconi M, Pesenti A, Grasselli G: Preparing for COVID-19 - Message from the ESICM President \& colleagues in Northern Italy. 2020

15. Acute Respiratory Distress Syndrome Network, Brower RG, Matthay MA, et al: Ventilation with lower tidal volumes as compared with traditional tidal volumes for acute lung injury and the acute respiratory distress syndrome. N Eng/ J Med 2000;342:1301-1308

16. Papazian L, Forel J, Gacouin A, et al: Neuromuscular blockers in early acute respiratory distress syndrome. N Engl J Med 2010;363:1107-1116

17. Guérin C, Reignier J, Richard J, et al: Prone positioning in severe acute respiratory distress syndrome. N Engl J Med 2013;368:2159-2168 
18. Wu Z, McGoogan JM: Characteristics of and Important Lessons From the Coronavirus Disease 2019 (COVID-19) Outbreak in China: Summary of a Report of 72314 Cases From the Chinese Center for Disease Control and Prevention. JAMA 2020;

19. Wu C, Chen X, Cai Y, et al: Risk Factors Associated With Acute Respiratory Distress Syndrome and Death in Patients With Coronavirus Disease 2019 Pneumonia in Wuhan, China. JAMA Intern Med 2020;

20. Camporota L: How to Ventilate in COVID-19. https://esicm-tv.org/webinar1 live 20-how-toventilate-in-covid-19.html Edition. 2020

21. Public Health England: COVID-19 personal protective equipment (PPE).

https://www.gov.uk/government/publications/wuhan-novel-coronavirus-infection-prevention-andcontrol/covid-19-personal-protective-equipment-ppe Edition.

22. National Tracheostomy Safety Project: Considerations for tracheostomy in the COVID-19 outbreak. 2020

23. McGrath BA, Brenner MJ, Warrillow SJ, et al: Tracheostomy in the COVID-19 era: global and multidisciplinary guidance. Lancet Respir Med 2020;8:717-725

24. Ciaglia P, Firsching R, Syniec C: Elective percutaneous dilatational tracheostomy. A new simple bedside procedure; preliminary report. Chest 1985;87:715-719

25. Wiedemann HP, Wheeler AP, Bernard GR, et al: Comparison of two fluid-management strategies in acute lung injury. N Eng/ J Med 2006;354:2564-2575

26. REMAP-CAP Trial: A Randomised, Embedded, Multi-factorial, Adaptive Platform Trial for Community-Acquired Pneumonia. https://www.remapcap.org Edition. 
27. RECOVERY Trial: Randomised Evaluation of COVID-19 Therapy. https://www.recoverytrial.net/ Edition.

28. ISARIC: International Severe Acute Respiratory and emerging Infection Consortium. https://isaric.tghn.org/ Edition.

29. The GenOMICC Study: The Genetics of Mortality in Critical Care. https://genomicc.org/ Edition.

30. NHS England and NHS Improvement: Clinical guide for supporting compassionate visiting arrangements for those receiving care at the end of life. https://www.england.nhs.uk/coronavirus/wpcontent/uploads/sites/52/2020/03/C0393-clinical-guide-for-supporting-compassionate-visitingarrangements-11-may-2020.pdf Edition. 2020

31. Moppett IK, Gardiner D, Harvey DJR: Guidance in an uncertain world. Br J Anaesth 2020;125:7-9

32. National Institute for Health and Care Excellence: COVID-19 rapid guideline: critical care in adults. https://www.nice.org.uk/guidance/ng159 Edition. NICE, 2020

33. Cook TM, El-Boghdadly K, McGuire B, et al: Consensus guidelines for managing the airway in patients with COVID-19: Guidelines from the Difficult Airway Society, the Association of Anaesthetists the Intensive Care Society, the Faculty of Intensive Care Medicine and the Royal College of Anaesthetists. Anaesthesia 2020;75:785-799

34. Amato MBP, Meade MO, Slutsky AS, et al: Driving pressure and survival in the acute respiratory distress syndrome. N Engl J Med 2015;372:747-755

35. Chikhani M, Das A, Haque M, et al: High PEEP in acute respiratory distress syndrome: quantitative evaluation between improved arterial oxygenation and decreased oxygen delivery. $\mathrm{Br} \mathrm{J}$ Anaesth 2016;117:650-658 
36. Gattinoni L, Chiumello D, Caironi P, et al: COVID-19 pneumonia: different respiratory treatments for different phenotypes? Intensive Care Med 2020;46:1099-1102 
Table 1. Baseline demographics and indicators of acute severity in patients admitted to Nottingham University Hospitals NHS Trust (NUH) critical care with confirmed coronavirus disease 2019 (COVID19) with comparison to national data obtained from the Intensive Care National Audit and Research Centre (ICNARC). NUHCC - Nottingham University Hospitals Critical Care, SD - Standard Deviation, IQR - Inter-Quartile Range, APACHE II - Acute Physiology And Chronic Health Evaluation II, $\mathrm{PaO}_{2}$ partial pressure of oxygen, $\mathrm{FiO}_{2}$ - Fraction of inspired oxygen. ${ }^{*}$ Source: ICNARC report on COVID-19 in critical care 12 June 2020.

\begin{tabular}{|c|c|c|}
\hline Demographics & NUHCC & National* \\
\hline \multicolumn{3}{|l|}{ Age at admission (years) $(\mathrm{N}=109)$} \\
\hline Mean (SD) & $56.5(13.7)$ & $58.7(12.6)$ \\
\hline Median (IQR) & $58(46,68)$ & $60(51,68)$ \\
\hline \multicolumn{3}{|l|}{ Sex, n (\%) (N=109) } \\
\hline Female & 37 (33.9) & $2864(29.3)$ \\
\hline Male & $72(66.1)$ & $6908(70.7)$ \\
\hline \multicolumn{3}{|l|}{ Currently or recently pregnant, $n$ (\% of females aged $16-49$ ) } \\
\hline Currently pregnant & $0(0)$ & $25(3.6)$ \\
\hline Recently pregnant (within 6 weeks) & $0(0)$ & $35(5.1)$ \\
\hline Not known to be pregnant & $37(100)$ & $633(91.3)$ \\
\hline \multicolumn{3}{|l|}{ Ethnicity, $n(\%)(N=103)$} \\
\hline White & 73 (70.9) & $6008(67.1)$ \\
\hline Mixed & $2(1.9)$ & $154(1.7)$ \\
\hline Asian & $13(12.6)$ & $1339(15.0)$ \\
\hline Black & $11(10.7)$ & $869(9.7)$ \\
\hline Other & $4(3.9)$ & $583(6.5)$ \\
\hline \multicolumn{3}{|l|}{ Body mass index, $\mathrm{n}(\%)(\mathrm{N}=108)$} \\
\hline$<18.5$ & $1(0.9)$ & $60(0.7)$ \\
\hline $18.5-<25$ & $30(27.8)$ & $2292(25.3)$ \\
\hline $25-<30$ & $29(26.9)$ & $3158(34.8)$ \\
\hline $30-<40$ & $36(33.3)$ & $2856(31.5)$ \\
\hline $40+$ & $12(11.1)$ & $710(7.8)$ \\
\hline Indicators of acute severity & NUHCC & National* \\
\hline Mechanically ventilated within first $24 \mathrm{~h}, \mathrm{n}(\%)(\mathrm{N}=109)$ & $68(62.4)$ & $5667(60.9)$ \\
\hline \multicolumn{3}{|l|}{ APACHE II Score } \\
\hline Mean (SD) & $15.3(5.5)$ & $14.9(5.3)$ \\
\hline Median (IQR) & $15(12,19)$ & $14(11,18)$ \\
\hline $\mathrm{PaO}_{2} / \mathrm{FiO}_{2}$ ratio $(\mathrm{kPa})$, median (IQR) & $15.9(11.7,20.6)$ & $15.7(11.2,22.0)$ \\
\hline \multicolumn{3}{|l|}{$\mathrm{PaO}_{2} / \mathrm{FiO}_{2}$ ratio, $\mathrm{n}(\%)(\mathrm{N}=108)$} \\
\hline$\leq 13.3 \mathrm{kPa}(\leq 100 \mathrm{mmHg})$ & $45(41.7)$ & $3306(37.2)$ \\
\hline$>13.3$ and $\leq 26.7 \mathrm{kPa}(>100$ and $\leq 200 \mathrm{mmHg}$ ) & $48(44.4)$ & $4267(48.0)$ \\
\hline$>26.7 \mathrm{kPa}(>200 \mathrm{mmHg})$ & $15(13.9)$ & 1309 (14.7) \\
\hline
\end{tabular}


Table 2. Initial laboratory results for patients admitted to NUHCC with COVID-19. IQR - Inter-Quartile Range, No. - Number, Ref. Reference, PT - Prothrombin Time, APTT - Activated Partial

Thromboplastin Time, CRP - C Reactive Protein, LDH - Lactate Dehydrogenase, AST - Aspartate Aminotransferase, ALT - Alanine Transaminase.

\section{Initial Laboratory Results}

\begin{tabular}{lccc|} 
Parameter & Median (IQR) & No. & Ref. range \\
Leukocytes & $8.98(7.05,11.21)$ & 109 & $4-11 \times 10^{9} / \mathrm{L}$ \\
Lymphocytes & $0.85(0.64,1.24)$ & 109 & $1-4 \times 10^{9} / \mathrm{L}$ \\
Platelets & $251(193,329)$ & 109 & $150-450 \times 10^{9} / \mathrm{L}$ \\
Creatinine & $82(62,108)$ & 109 & $59-104 \mu \mathrm{mol} / \mathrm{L}$ \\
PT & $11.4(10.9,11.8)$ & 109 & $10-12 \mathrm{sec}$ \\
APTT & $24.9(23.2,27.9)$ & 109 & $21-29 \mathrm{sec}$ \\
Fibrinogen & $6.01(5.19,7.22)$ & 42 & $1.8-4 \mathrm{~g} / \mathrm{L}$ \\
D-Dimer & $1193(711,2070)$ & 38 & $<500 \mu \mathrm{g} / \mathrm{L}$ \\
CRP & $222(148,293)$ & 109 & $0-10 \mathrm{mg} / \mathrm{L}$ \\
Lactate & $1.2(1,1.9)$ & 109 & $0.5-1.6 \mathrm{mmol} / \mathrm{L}$ \\
Ferritin & $1384(649,2158)$ & 56 & $25-350 \mu \mathrm{gg} / \mathrm{L}$ \\
LDH & $995(769,1355)$ & 26 & $220-450 \mathrm{U} / \mathrm{L}$ \\
Troponin & $18(11.5,132.3)$ & 36 & $0-59 \mathrm{ng} / \mathrm{L}$ \\
Bilirubin & $12(8,15)$ & 109 & $0-21 \mu \mathrm{mol} / \mathrm{L}$ \\
AST & $82(61,116)$ & 71 & $0-35 \mathrm{U} / \mathrm{L}$ \\
ALT & $43(28,63)$ & 105 & $0-45 \mathrm{U} / \mathrm{L}$ \\
\hline
\end{tabular}


Table 3. Outcome and length of stay for patients admitted to NUHCC with COVID-19. NUHCC Nottingham University Hospitals Critical Care, IQR - Inter-Quartile Range, SD - Standard Deviation.

*Source: ICNARC report on COVID-19 in critical care 12 June 2020.

\begin{tabular}{|c|c|c|}
\hline Outcome and length of stay & NUHCC & National* \\
\hline \multicolumn{3}{|l|}{ Outcome at end of critical care, $n(\%)(N=100)$} \\
\hline Discharged & $74(74.0)$ & $5190(58.4)$ \\
\hline Died & $26(26.0)$ & $3701(41.6)$ \\
\hline \multicolumn{3}{|l|}{ Outcome at end of hospital stay, $n(\%)(\mathrm{N}=95)$} \\
\hline Discharged & $68(71.6)$ & \\
\hline Died & $27(28.4)$ & \\
\hline \multicolumn{3}{|c|}{$\begin{array}{l}\text { Outcome at end of critical care - Mechanically ventilated, } n(\%) \\
(\mathrm{N}=79)\end{array}$} \\
\hline Survivors & $57(72.2)$ & \\
\hline Non-survivors & $22(27.8)$ & \\
\hline \multicolumn{3}{|c|}{$\begin{array}{l}\text { Outcome at end of hospital stay - Mechanically ventilated, } n(\%) \\
(\mathrm{N}=74)\end{array}$} \\
\hline Discharged & $52(70.3)$ & \\
\hline Died & $22(29.7)$ & \\
\hline \multicolumn{3}{|c|}{ Length of stay in critical care (days), median (IQR) ( $N=100)$} \\
\hline Survivors & $13(7,27)$ & $11.5(4,25)$ \\
\hline Non-Survivors & $8(4,11)$ & $9(5,15)$ \\
\hline Survivors, Mean (SD) & $17.3(13.4)$ & \\
\hline Non-Survivors, Mean (SD) & $9.2(6.1)$ & \\
\hline \multicolumn{3}{|c|}{$\begin{array}{l}\text { Length of stay - ICU admission to hospital discharge (days), } \\
\text { median (IQR) ( } N=95 \text { ) }\end{array}$} \\
\hline Survivors & $22(14,35)$ & \\
\hline Non-Survivors & $9(4,12)$ & \\
\hline Survivors, Mean (SD) & $24.6(14.1)$ & \\
\hline Non-Survivors, Mean (SD) & $9.1(6.2)$ & \\
\hline \multicolumn{3}{|c|}{$\begin{array}{l}\text { Length of stay - Hospital admission to hospital discharge (days), } \\
\text { median (IQR) ( } N=95 \text { ) }\end{array}$} \\
\hline Survivors & $24(15,36)$ & \\
\hline Non-Survivors & $11(7,18)$ & \\
\hline Survivors, Mean (SD) & $26.5(14.4)$ & \\
\hline Non-Survivors, Mean (SD) & $11.1(6.6)$ & \\
\hline \multicolumn{3}{|l|}{$\begin{array}{l}\text { Duration of mechanical ventilation (days), } \\
\text { median (IQR) ( } N=79)\end{array}$} \\
\hline Survivors & $19(9,27)$ & \\
\hline Non-survivors & $10(5.8,12.8)$ & \\
\hline Survivors, Mean (SD) & $19.6(11.7)$ & \\
\hline Non-Survivors, Mean (SD) & $10.5(6.3)$ & \\
\hline
\end{tabular}


Table 4. Summary data for first seven days of mechanical ventilation in patients admitted with COVID-19 to NUHCC. Updated ventilation guidance was implemented on $9^{\text {th }}$ April. IQR - InterQuartile Range, SD - Standard Deviation, PEEP - Positive End Expiratory Pressure, DP - Driving Pressure, PAWP - Peak Airway Pressure, Vt - Tidal Volume (mL. $\mathrm{Kg}^{-1}$ predicted body weight), MAWP Mean Airway Pressure

\section{Ventilation Data Summary}

Parameter Overall

Before $9^{\text {th }}$ April

After $\mathbf{9}^{\text {th }}$ April

\begin{tabular}{|c|c|c|c|c|c|c|}
\hline & $\begin{array}{l}\text { Median } \\
\text { (IQR) }\end{array}$ & $\begin{array}{l}\text { Mean } \\
\text { (SD) }\end{array}$ & $\begin{array}{l}\text { Median } \\
\text { (IQR) }\end{array}$ & $\begin{array}{l}\text { Mean } \\
\text { (SD) }\end{array}$ & $\begin{array}{l}\text { Median } \\
\text { (IQR) }\end{array}$ & $\begin{array}{l}\text { Mean } \\
\text { (SD) }\end{array}$ \\
\hline PEEP $\left(\mathrm{cmH}_{2} \mathrm{O}\right)$ & $10(8,14)$ & $10.0(4.43)$ & $12(8,14)$ & $10.3(4.6)$ & $10(8,12)$ & $9.3(3.9)$ \\
\hline $\mathrm{DP}\left(\mathrm{cmH}_{2} \mathrm{O}\right)$ & $14(11,16)$ & 14.3 (5.9) & $14(11,16)$ & 14.4 (5.8) & $14(11,16)$ & $14.1(6.2)$ \\
\hline PAWP $\left(\mathrm{cmH}_{2} \mathrm{O}\right)$ & $25(22,28)$ & 24.5 (5.3) & $26(22,29)$ & $24.9(5.3)$ & $24(21,27)$ & $23.4(5.1)$ \\
\hline $\mathrm{Vt}\left(\mathrm{mL} \cdot \mathrm{Kg}^{-1}\right)$ & $7.1(6,8)$ & $7.4(1.8)$ & $6.9(6,8)$ & $7.3(1.8)$ & $7.4(7,9)$ & 7.7 (1.8) \\
\hline MAWP $\left(\mathrm{cmH}_{2} \mathrm{O}\right)$ & $17.7(15,20)$ & 17.7 (3.6) & $18.4(16,20)$ & $18.1(3.5)$ & $16(14,19)$ & $16.6(3.7)$ \\
\hline
\end{tabular}


Table 5. NUHCC outcomes for those admitted with COVID-19 by patient characteristics in comparison to national data. NUHCC - Nottingham University Hospitals Critical Care, BMI- Body Mass Index. *Source: ICNARC report on COVID-19 in critical care 12 June 2020.

\begin{tabular}{|c|c|c|c|c|}
\hline \multicolumn{5}{|c|}{ Outcomes by Patient Characteristics } \\
\hline & $\begin{array}{l}\text { Discharged } \\
\text { n (\%) }\end{array}$ & $\begin{array}{l}\text { Died } \\
\text { n (\%) }\end{array}$ & $\begin{array}{c}\text { Discharged } \\
\text { n (\%) }\end{array}$ & $\begin{array}{l}\text { Died } \\
\text { n (\%) }\end{array}$ \\
\hline \multicolumn{5}{|c|}{ Age at admission (years) } \\
\hline $16-39$ & $13(81.3)$ & $3(18.8)$ & $603(84.5)$ & $111(15.5)$ \\
\hline $40-49$ & $14(87.5)$ & $2(12.5)$ & 935 (77.9) & $266(22.1)$ \\
\hline $50-59$ & $22(81.5)$ & $5(18.5)$ & $1582(64.6)$ & $868(35.4)$ \\
\hline $60-69$ & $13(56.5)$ & $10(43.5)$ & $1334(51.1)$ & 1275 (48.9) \\
\hline 70-79 & $10(66.7)$ & $5(33.3)$ & $628(38.2)$ & $1016(61.8)$ \\
\hline $80+$ & $2(66.7)$ & $1(33.3)$ & 107 (39.5) & $164(60.5)$ \\
\hline \multicolumn{5}{|l|}{ Sex } \\
\hline Female & $27(75)$ & $9(25)$ & 1656 (63.5) & $952(36.5)$ \\
\hline Male & $47(73.4)$ & $17(26.6)$ & $3534(56.3)$ & $2747(43.7)$ \\
\hline \multicolumn{5}{|l|}{ BMI } \\
\hline$<25$ & $18(62.1)$ & $11(37.9)$ & $1223(57.7)$ & $897(42.3)$ \\
\hline $25-<30$ & $19(76)$ & $6(24)$ & $1621(55.7)$ & $1290(44.3)$ \\
\hline $30-<40$ & $27(81.8)$ & $6(18.2)$ & 1629 (61.9) & 1001 (38.1) \\
\hline $40+$ & $8(72.7)$ & $3(27.3)$ & $413(63.3)$ & $239(36.7)$ \\
\hline \multicolumn{5}{|l|}{ Ethnicity } \\
\hline White & $50(73.5)$ & $18(26.5)$ & $3290(59.5)$ & 2243 (40.5) \\
\hline Mixed & $1(50)$ & $1(50)$ & $70(53.0)$ & $62(47.0)$ \\
\hline Asian & $8(80.0)$ & $2(20)$ & $633(52.7)$ & $569(47.3)$ \\
\hline Black & $7(70)$ & $3(30)$ & $425(55.2)$ & $345(44.8)$ \\
\hline Other & $2(50)$ & $2(50)$ & $338(65.0)$ & $182(35.0)$ \\
\hline
\end{tabular}


Figure 1. Incidence of thromboembolic events by week of admission, annotated with evolution of guidance for venous thromboembolism prophylaxis. LMWH - Low Molecular Weight Heparin, PE Pulmonary Embolism, CVA - Cerebrovascular Accident.

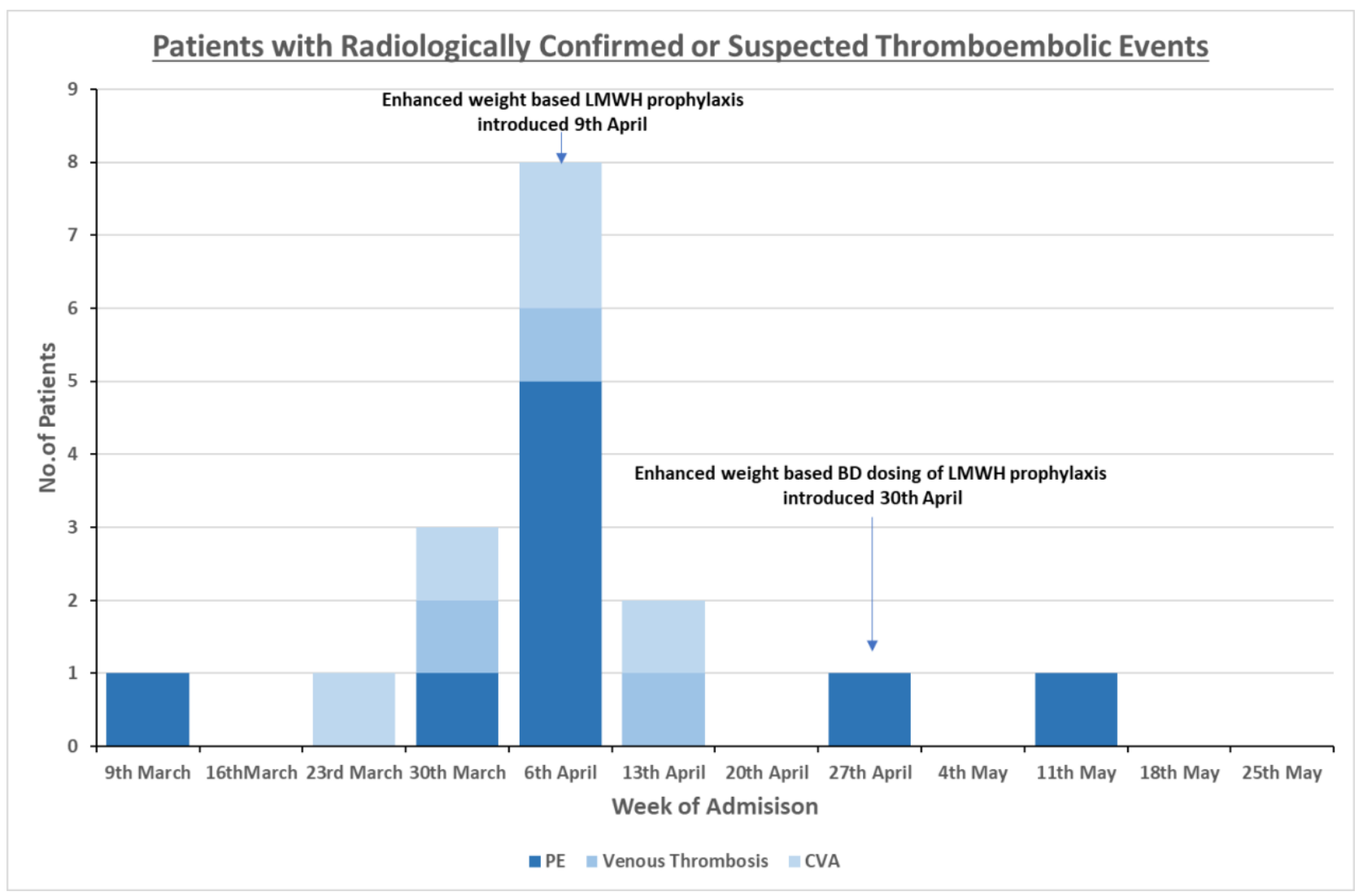


Figure 2. Cohort flow of patients admitted with COVID-19 to NUHCC.

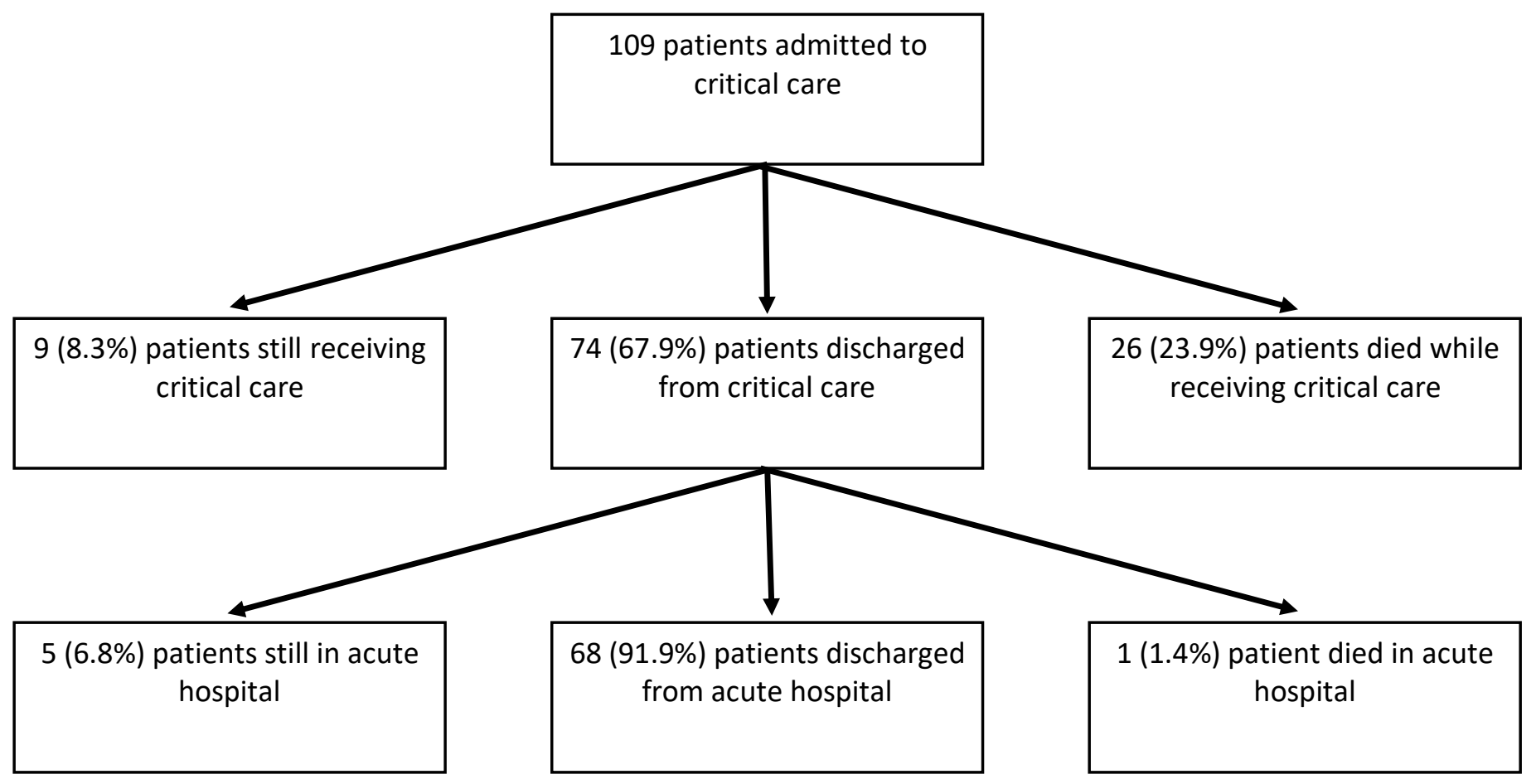


Figure 3. Number of admissions, mortality, APACHE II score and cumulative number of simultaneous confirmed COVID-19 cases in NUHCC by week, during evaluation period. ICU - Intensive Care Unit, APACHE II - Acute Physiology And Chronic Health Evaluation II.

\section{ICU Outcome by Week of Admission}

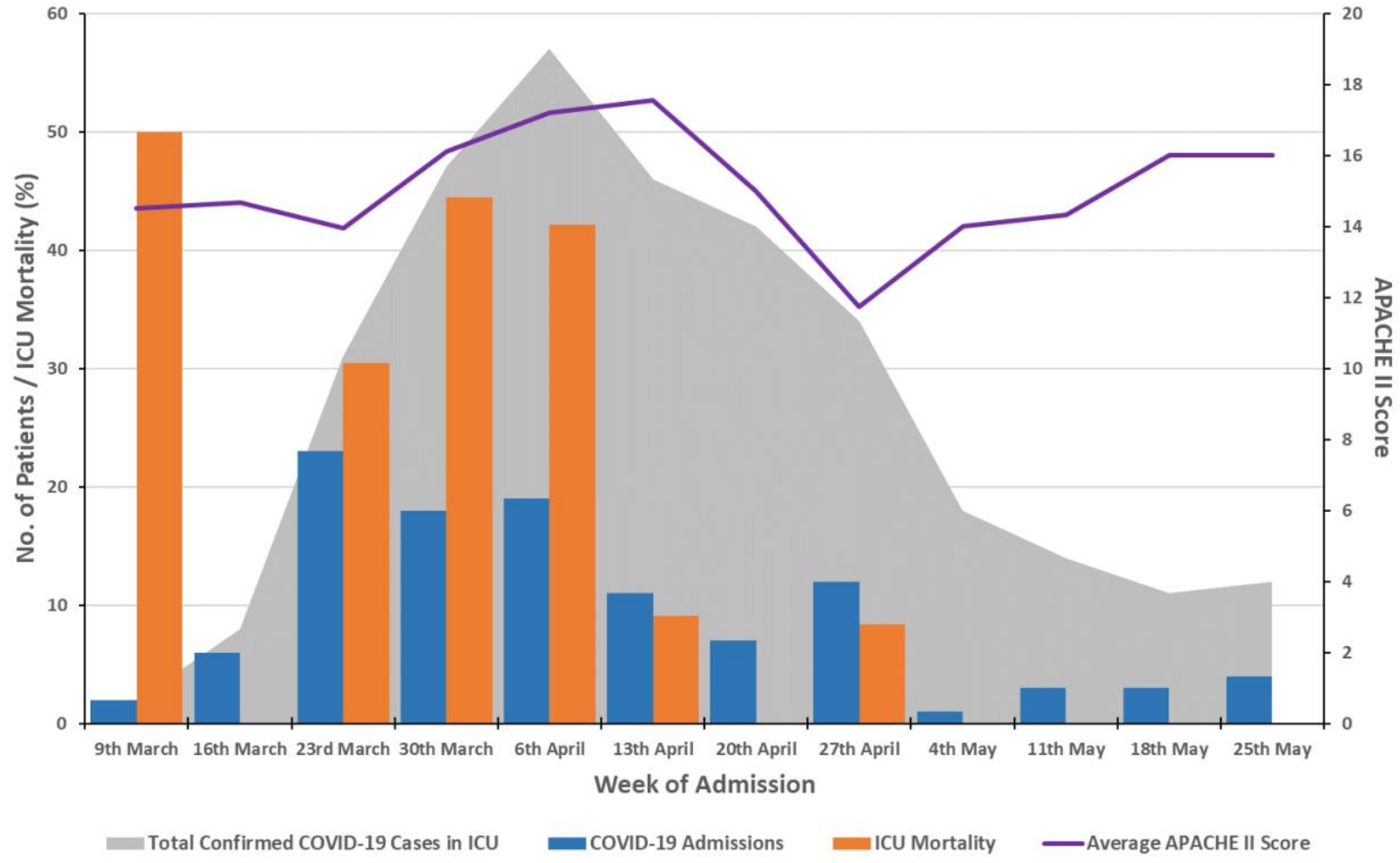


Appendix

V1.11 
Appendix I. NUHCC Ventilation Strategy for COVID-19.

Appendix II - NUHCC COVID-19 Renal Management Strategy.

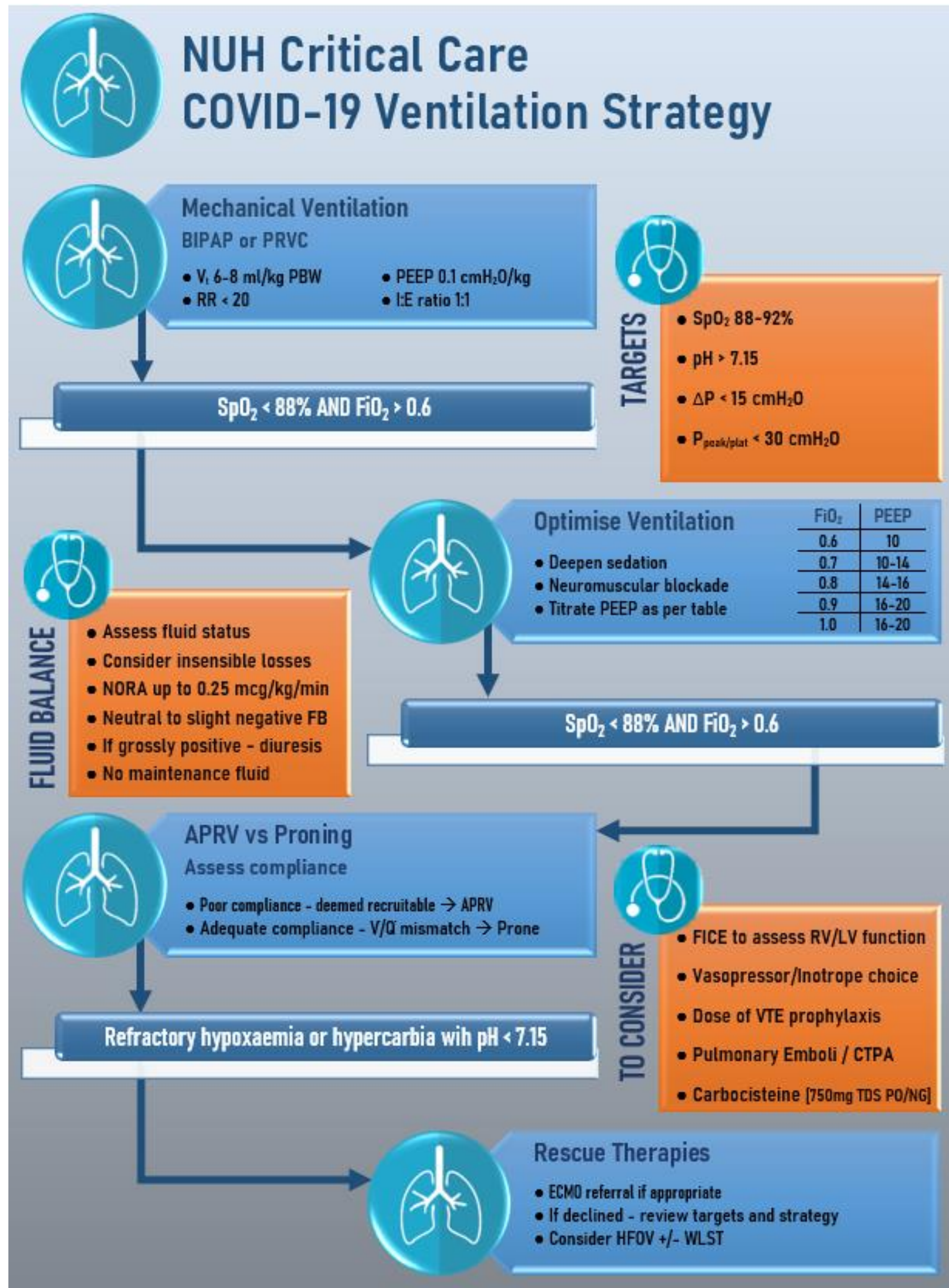


NHS

Nottingham University Hospitals

\section{NUH Critical Care:COVID-19 Renal Management Strategy}

This document has been produced to offer suggestions on the management of patients admitted to critical care with COVID-19 infection at Nottingham University Hospitals.

\section{General considerations}

- The COVID-19 pandemic presents an unprecedented challenge

- COVID-19 primarily causes an acute respiratory illness progressing to ARDS - but it is a multi-system disease

\section{Specific considerations}

- The reported rate of acute kidney injury in patients admitted to hospital with COVID-19 is between $3-9 \%$

- The exact mechanism is unclear

- $44 \%$ of patients were found to have proteinuria

$26 \%$ had microscopic haematuria

- AKI is an independent risk factor for mortality in patients with COVID-19

Suggestions for the management of patients with COVID-19

Don't add insult to injury:

Review medication chart and omit drugs that are likely to increase the risk of AKI:

- ACE-inhibitors (-prils)

- Angiotensin-2 receptor blockers (-sartans)

Non-steroidal anti-inflammatory drugs

Potassium sparing diuretics (Spironolactone)

D Thiazide diuretics

Management of fluid balance

- Fluid overload in ARDS thought to cause increased mortality

- However - dehydration is a risk factor for AKI

- Below is a pragmatic decision aid offering suggestions on fluid management in COVID-19:

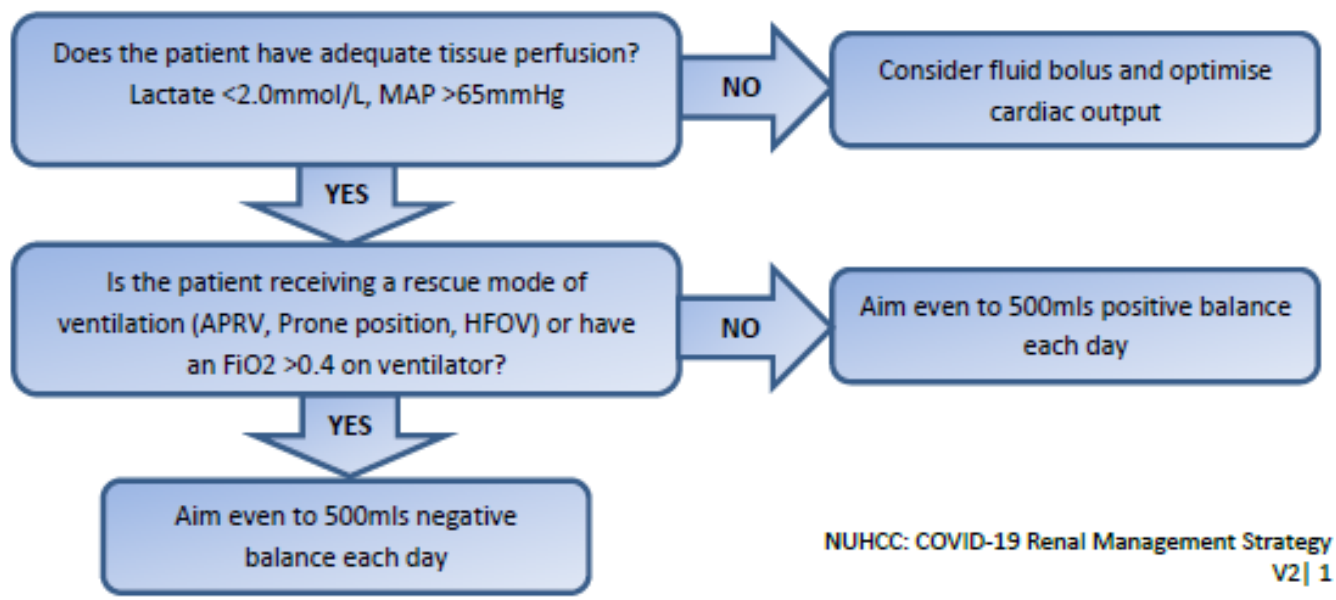


NHS

Nottingham University Hospitals

NHS Trust

Suggested strategies for avoiding fluid overload

Minimise fluid intake

- Avoid use of maintenance fluids

- Use concentrated enteral feed

- Use lowest volume of fluid in necessary infusions and drugs (such as glucose infusions for sliding scales)

Consider loop diuretics

- Patients passing more than $500 \mathrm{~m} / \mathrm{s}$ of urine per day may benefit from loop diuretics

- Furosemide given intravenously is the preferred loop diuretic in critical care

\begin{tabular}{|c|c|c|}
\hline Creatinine less than 99 & Furosemide $40 \mathrm{mg}$ twice per day & $\begin{array}{l}\text { If insufficient response increase } \\
\text { to } 80 \mathrm{mg} \text { twice per day }\end{array}$ \\
\hline Creatinine between 100 and 199 & Furosemide $80 \mathrm{mg}$ twice per day & \begin{tabular}{|l} 
If insufficient response increase \\
to $120 \mathrm{mg}$ twice per day
\end{tabular} \\
\hline Creatinine greater than 200 & Furosemide $120 \mathrm{mg}$ twice per day & $\begin{array}{l}\text { If insufficient response seek ICU } \\
\text { consultant advise. May be } \\
\text { diuretic resistant }\end{array}$ \\
\hline
\end{tabular}

- Furosemide can be given by bolus or 24-hour infusion. Starting doses depend on renal function.

- Furosemide infusions are prescribed as $500 \mathrm{mg}$ made up to $50 \mathrm{mls}$ with $0.9 \%$ saline given at $1-2 \mathrm{mls} /$ hour

- Additional diuretics may be necessary to achieve the desired fluid balance.

- There are two enteral options - the choice of which will depend on the potassium level that day:

- If $\mathrm{K}^{+}$is $>5 \mathrm{mmol} / \mathrm{l}$ - add metolazone $5 \mathrm{mg}$ once per day via the nasogastric tube

- If $\mathrm{K}^{+}$is $<5 \mathrm{mmol} / \mathrm{l}$ - add amiloride $5 \mathrm{mg}$ twice per day via the nasogastric tube

\section{Renal Replacement Therapy}

Specific considerations

- It is likely the need for RRT will exceed the current capacity at NUHCC - placing a strain on the supply chain of consumables and machines

- Decisions to start and continue RRT must be made by the responsible ICU consultant and based on an ethical framework

- RRT should be considered when:

AKI 3 complicated by one or more of:

- Refractory hyperkalaemia

- Metabolic acidosis

- Fluid overload refractory to diuretics
$\mathrm{K}^{+}>6.5 \mathrm{mmol} / \mathrm{I}$

$\mathrm{pH}<7.1$

Defined as fluid overload in a patient on a rescue mode of ventilation not achieving a negative fluid balance on maximal diuretic therapy

NUHCC: COVID-19 Renal Management Strategy 
NHS

Nottingham University Hospitals

We Listen

NHS Trust

We Care

Once the decision to start RRT has been made by the ICU consultant - the following steps should be considered:

\begin{tabular}{|l|l|l|l|}
\hline \multicolumn{1}{|c|}{ Preference } & \multicolumn{1}{|c|}{ Site } & \multicolumn{1}{c|}{ Length of line } & \multicolumn{1}{c|}{ Ideal tip position } \\
\hline First & Right Internal Jugular & $15 \mathrm{~cm}$ vascath & Tip in top of right atrium \\
Second & Femoral veins & $20 \mathrm{~cm}$ vascath & Inserted to the hub \\
\hline Third & Left Internal Jugular & $20 \mathrm{~cm}$ vascath & Tip in top of right atrium \\
Fourth & Subclavian vein & $15-20 \mathrm{~cm}$ vascath & Tip in top of right atrium \\
\hline
\end{tabular}

- Ultrasound guided dialysis catheter placement by an appropriately skilled practitioner

- The catheter lumens should all aspirate and flush freely before securing the line

- Preferred catheter site as per table above:

\section{The RRT prescription}

During the COVID-19 pandemic we will use a default RRT prescription designed to maximise the longevity of the circuit and permit ultrafiltration. In non-COVID-19 patients, please seek advice from the ICU consultant.

\section{Mode}

- CVVHDF - continuous veno-venous haemodiafiltration will be the default mode

\section{Dose}

- The recommended effluent dose is $35 \mathrm{mis} / \mathrm{kg} /$ hour

The pre-dilution to post-dilution ratio should be $70: 30$

The dialysate should be prescribed as $1000 \mathrm{mls}$

- It may be reasonable to offer an intermittent therapy: 24 hours on - 24 hours off - if necessary

- A decision to discontinue the therapy should be made by the ICU consultant

Fluid balance

- Body fluid assessment should inform a fluid removal target

- It could be possible to aim for $1000 \mathrm{ml}-2000 \mathrm{ml}$ negative balance over the course of a 12-hour treatment

\section{Anticoagulation}

- There are reports of clotting abnormalities in patients with COVID-19

- Anticoagulation will improve efficiency of treatment - but should be balanced against the risk of bleeding

- The default anticoagulant will be low molecular weight heparin (dalteparin see prescription chart)

\section{Stopping RRT}

- It is safe to pause RRT once $\mathrm{pH}>7.3$ and $\mathrm{K}^{+}<5.5 \mathrm{mmol} / \mathrm{l}$

- It is difficult to be certain when a patient has regained independent renal function

NUHCC: COVID-19 Renal Management Strategy 
NWS

Nottingham University Hospitals

We Care
NHS Trust

Resolution of underlying cause and urine output of $>1000 \mathrm{mls}$ per day are predictors of weaning from RRT

Troubleshooting

The most common cause for high access pressures and the loss of a circuit is poor vascular access placement.

The bedside nurse will manipulate the line into optimal position - if the problem persists consider:

o Lying the patient flat

- Is a fluid bolus appropriate? (this is unlikely to be the answer in fluid overloaded patients)

- If the patient is in the prone position - is it worth turning them supine?

- Provided solute clearance is acceptable $\left(\mathrm{K}^{+}<6 \mathrm{mmol} / \mathrm{l}\right)$ - increasing the pre and post-dilution ratio to $90: 10$ may be helpful - but will impair solute clearance

- Reducing the effluent rate to $25 \mathrm{ml} / \mathrm{kg} /$ hour could be considered

- Consider starting or increasing the dose of anticoagulation

- A new line may be necessary

Note: Rising transmembrane pressures often herald imminent loss of circuit. Washing the circuit back before it clots will reduce the need for transfusions.

Failure to achieve adequate solute clearance may be a consequence of using higher pre and post dilution ratios.

Failure to clear potassium should lead the practitioner to consider:

- Excessive potassium release from virus induced rhabdomyolysis or compartment syndrome:

- Check CK and examine patient for compartment syndrome

- Check the drug card and infusion chart for sources of potassium:

- Enteral potassium, potassium acid phosphate infusions

- Medications such as co-trimoxazole, ACE-inhibitors, spironolactone or amiloride

- Ultimately the dose of RRT may need to be increased by:

- Adjusting the pre and post-dilution ratio to $50: 50$

- Increasing the treatment time

- Increasing the effluent rate

Worsening $\mathrm{pH}$

- Permissive hypercapnia will likely lead to a rise in the bicarbonate. RRT may lead to a fall in the serum bicarbonate and therefore a reduction in $\mathrm{pH}$.

- If the clearance is acceptable then stopping dialysate is advised.

D An $8.4 \%$ sodium bicarbonate infusion at $25 \mathrm{mls} /$ hour may be necessary.

Richard Greenhow

Consultant in critical care and renal medicine

'Naicker S et al. The novel Coronavirus 2019 epidemic and kidneys. Kidney International. 2020. DOI http5://doi.org/10.106/j.kint.2020.03.001

NUHCC: COVID-19 Renal Management Strategy 
Appendix III. Venous thromboembolism prophylaxis regimen updated on $9^{\text {th }}$ April and $30^{\text {th }}$ April. Guidance prior to COVID-19 was 40mg Enoxaparin once daily for those between 50 - 100kg, adjustments were made for creatinine clearance and extremes of weight.

Updated Guidance on $9^{\text {th }}$ April: Enoxaparin doses for COVID-19 confirmed or suspected patients.

\begin{tabular}{|l|c|c|c|c|}
\hline \multirow{2}{*}{ Renal Function } & \multicolumn{4}{|c|}{ Weight } \\
\cline { 2 - 5 } & $<50 \mathrm{~kg}$ & $50-100 \mathrm{~kg}$ & $100-150 \mathrm{~kg}$ & $>150 \mathrm{~kg}$ \\
\hline $\mathrm{CrCl} \geq 30 \mathrm{ml} / \mathrm{min}$ & $20 \mathrm{mg}$ OD & $40 \mathrm{mg}$ OD & $40 \mathrm{mg} \mathrm{BD}$ & $60 \mathrm{mg} \mathrm{BD}$ \\
\hline $\mathrm{CrCl} 15-30 \mathrm{ml} / \mathrm{min}$ & $20 \mathrm{mg} \mathrm{OD}$ & $20 \mathrm{mg}$ OD & $40 \mathrm{mg}$ OD & $60 \mathrm{mg}$ OD \\
\hline $\mathrm{CrCl}<15 \mathrm{ml} / \mathrm{min}$ & \multicolumn{4}{|c|}{$20 \mathrm{mg}$ OD } \\
\hline
\end{tabular}

Updated Guidance on $30^{\text {th }}$ April: Enoxaparin doses for COVID-19 confirmed or suspected patients.

\begin{tabular}{|l|c|c|c|c|}
\hline \multirow{2}{*}{ Renal Function } & \multicolumn{4}{|c|}{ Weight } \\
\cline { 2 - 5 } & $<50 \mathrm{~kg}$ & $50-100 \mathrm{~kg}$ & $100-150 \mathrm{~kg}$ & $>150 \mathrm{~kg}$ \\
\hline $\mathrm{CrCl} \geq 30 \mathrm{ml} / \mathrm{min}$ & $20 \mathrm{mg} \mathrm{BD}$ & $40 \mathrm{mg} \mathrm{BD}$ & $60 \mathrm{mg} \mathrm{BD}$ & $80 \mathrm{mg} \mathrm{BD}$ \\
\hline $\mathrm{CrCl} 15-30 \mathrm{ml} / \mathrm{min}$ & $20 \mathrm{mg} \mathrm{OD}$ & $20 \mathrm{mg} \mathrm{OD}$ & $60 \mathrm{mg}$ OD & $80 \mathrm{mg} \mathrm{OD}$ \\
\hline $\mathrm{CrCl}<15 \mathrm{ml} / \mathrm{min}$ & \multicolumn{5}{|c|}{$20 \mathrm{mg} \mathrm{OD}$} \\
\hline
\end{tabular}


Figures

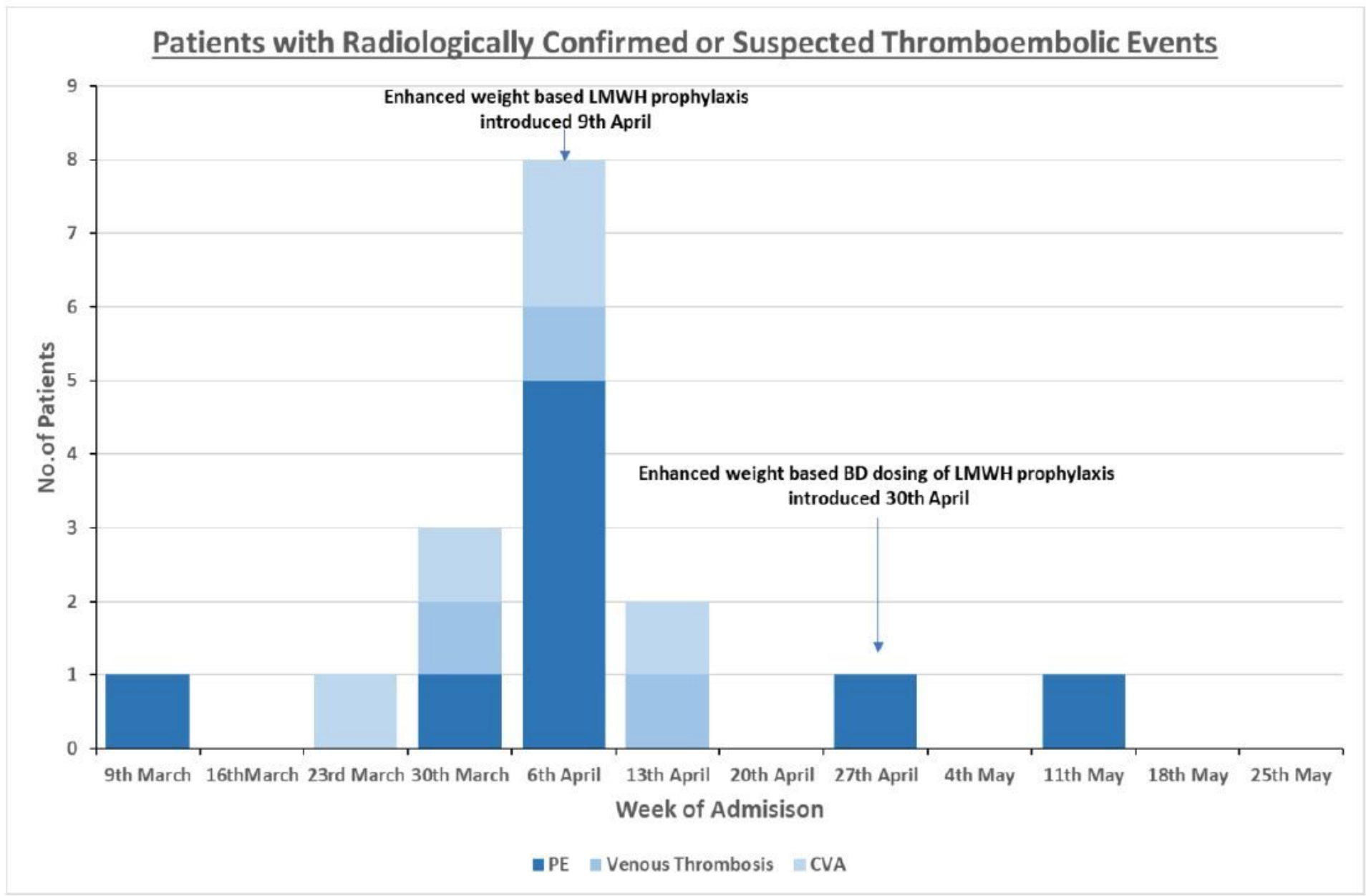

\section{Figure 1}

Incidence of thromboembolic events by week of admission, annotated with evolution of guidance for venous thromboembolism prophylaxis. LMWH - Low Molecular Weight Heparin, PE - Pulmonary Embolism, CVA - Cerebrovascular Accident. 


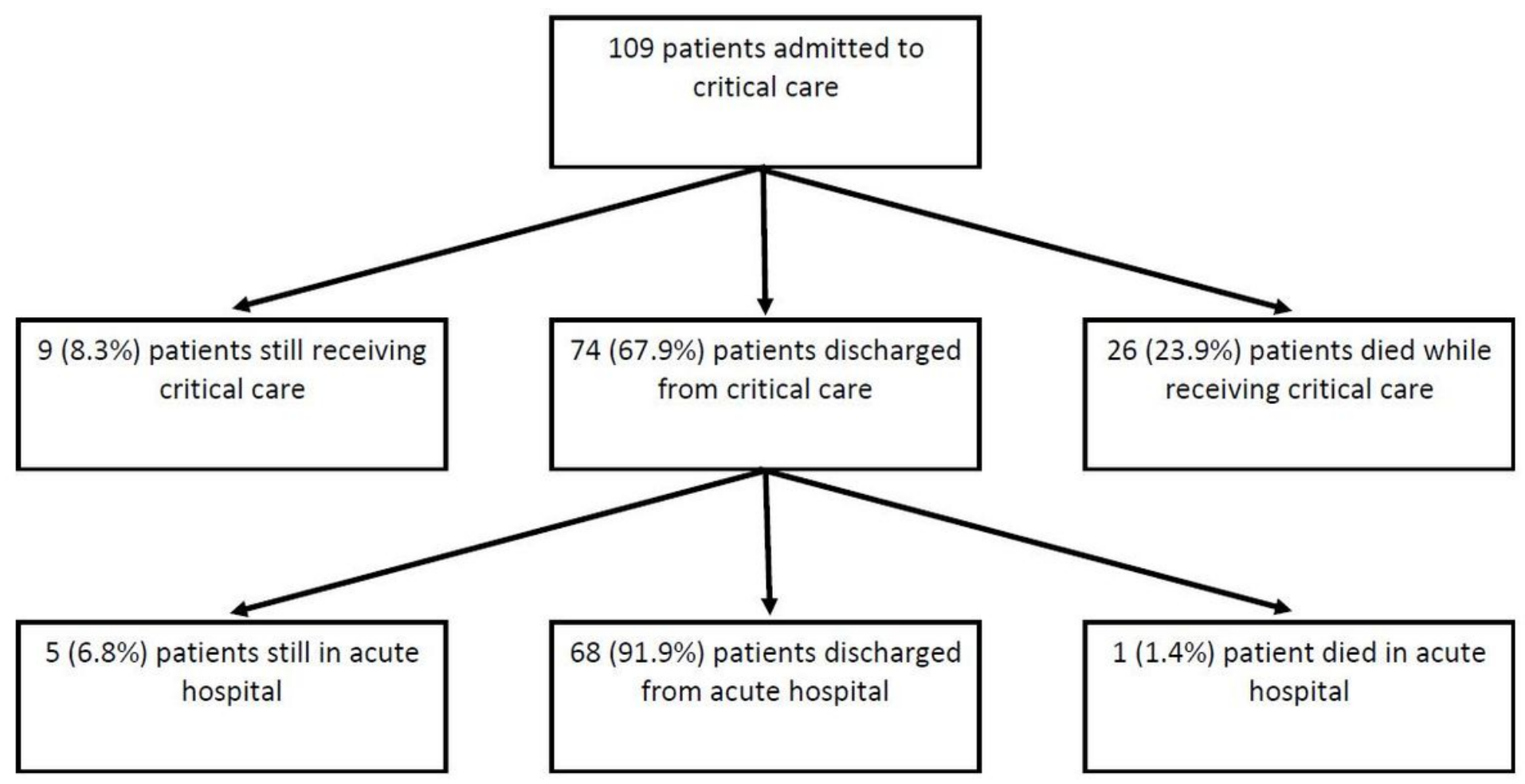

Figure 2

Cohort flow of patients admitted with COVID-19 to NUHCC.

\section{ICU Outcome by Week of Admission}

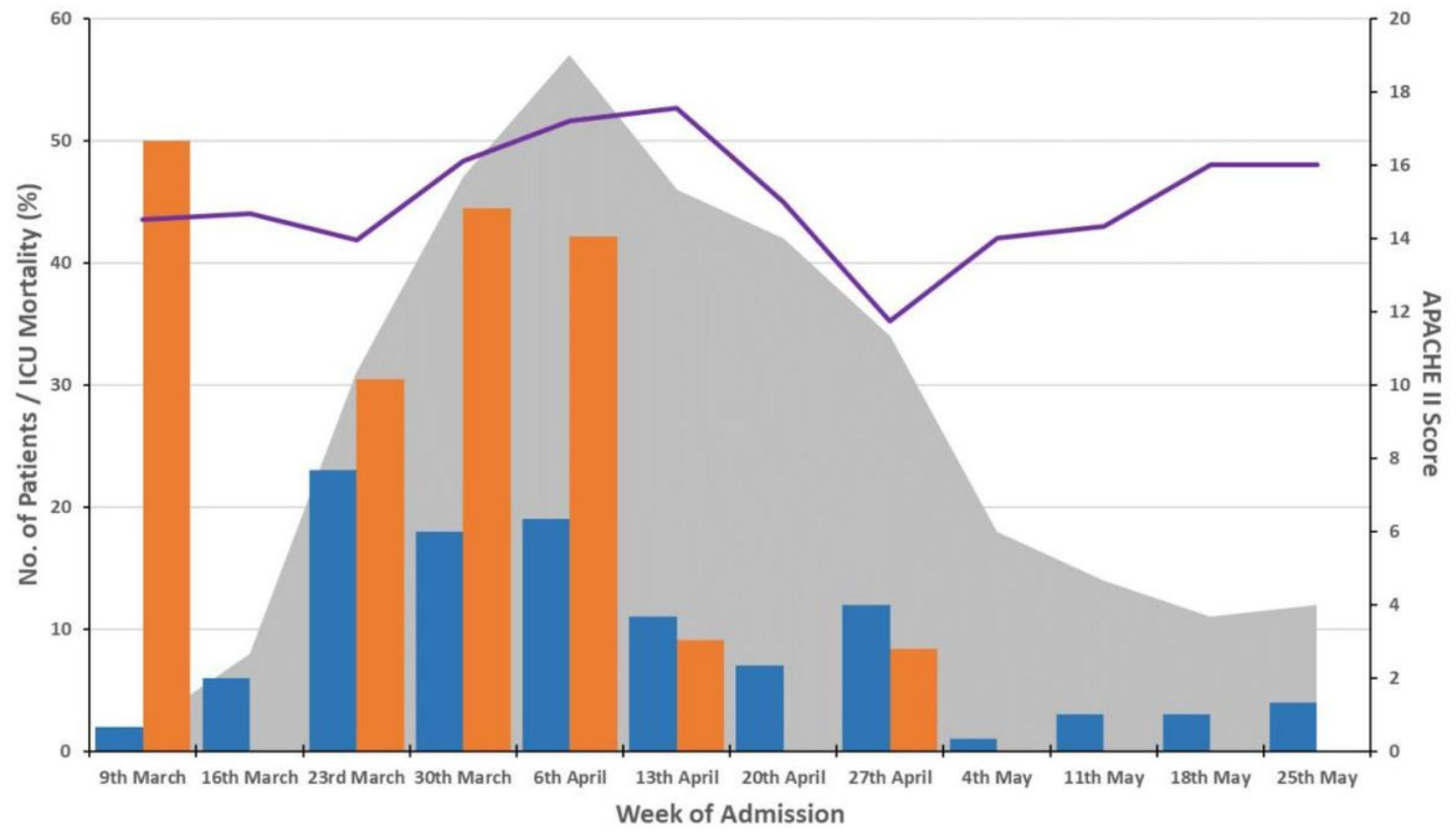




\section{Figure 3}

Number of admissions, mortality, APACHE II score and cumulative number of simultaneous confirmed

COVID-19 cases in NUHCC by week, during evaluation period. ICU - Intensive Care Unit, APACHE II - Acute Physiology And Chronic Health Evaluation II. 